Vol.2, No. 2, Mei. 2019

\title{
TAX MINIMIZATION SEBAGAI PEMODERASI PADA PENGARUH TUNNELLING INCENTIVE DAN DEBT CONVENANT TERHADAP KETETAPAN TRANSFER PRICING
}

\author{
Sri Yulianti ${ }^{1}$ ), Sistya Rachmawati \\ Universitas Trisakti \\ Email:yuliantisri13@gmail.com
}

\begin{abstract}
The aims to this study was to provide empirical evidence of the effect of tunneling incentives and debt convenants on transfer pricing with tax minimization as moderating. In this study, tunneling incentive was measured through the number of foreign rights share ownership percentage of the number of outstanding shares, debt convenant measured debt policy with DER in each manufacturing company.The sample used in the study was 15 manufacturing companies with purposive sampling of 60 data in 2014-2017 which were listed on the IDX. Data is taken from annual reports listed on the IDX since 2014. Tests conducted in this study are using panel regression analysis with the program eviews 8.1. The results of the study indicate that the tunneling incentive has a significant positive effect on the transfer pricing policy while the debt convenant has a negative effect not significant on the transfer pricing policy. Tax minimization does not moderate the influence between tunneling incentives and debt convenants on transfer pricing decisions.
\end{abstract}

Keywords: tunnelling incentive, tax minimization, debt convenant, transfer pricing.

\begin{abstract}
Abstrak
Tujuan penelitian ini untuk memberikan kebenaran pengaruh tunnelling incentive dan debt convenant terhadap transfer pricing dengan tax minimization sebagai pemoderasi. Dalam penelitian ini, tunnelling incentive diukur melalui jumlah kepemilikan saham hak asing prosentase jumlah saham beredar, Debt convenant diukur strategi hutang dengan DER, dan tax minimization diukur melalui beban pajak dengan prosentase laba kena pajak di masing-masing perusahaan manufaktur. Penelitian ini menggunakan sample yang didapat dari perusahaan manufaktur dengan jumlah 15 perusahaan dengan purposive sampling 60 data laporan keuangan sejak tahun 2014-2017 yang tercatat di BEI. Perolehan data penelitian dari laporan tahunan yang tercatat di BEI sejak 2014. Pengujian pada penelitian ini menggunakan analisis regresi panel pada program eviews 8.1. Hasil dari penelitian menunjukkan bahwa tunnelling incentive berpengaruh positif
\end{abstract}


signifikan terhadap strategi transfer pricing sedangkan debt convenant berpengaruh negatif tidak signifikan terhadap strategi transfer pricing. Tax minimization tidak memoderasi pengaruh antara tunnelling incentive dan debt convenant terhadap ketetapan transfer pricing.

Kata kunci: tunnelling incentive, tax minimization, debt convenant, transfer pricing.

\section{PENDAHULUAN}

Sejak disahkan GATT berubah menjadi World Trade Organization, kesejagatan (globalisasi) menggenjot perusahaan multinasional. Akibatnya, transaki antar negara pun meningkat, sehingga batas antarnegara satu dengan batas negara lainnya hampir tidak ada. Sama halnya dengan modal yang ditanam oleh satu negara ke negara lain sehingga akan meningkatkan arus perdagangan/kegiatan usaha internasional atau lintas negara. Keadaan dari fenomena tersebut kita perlu memiliki kiat untuk menggali potensi penerimaan dari kegiatan tersebut. Sebagaian besar international trade transactions melibatkan multinational company dalam satu group (intra-group transaction) dan semakin kompleks sebab tidak hanya mengimplikasikan barang modal, jasa, dan harta tak bergerak (kekayaan intelektual). Sehingga kompleksitas perihal menganalisis guna kepentingan pemajakan.

Berlandaskan "UU No. 36 Thn. 2008 tentang Pajak Penghasilan Pasal 18 ayat". (4) terkait adanya hubungan antara Wajib Pajak Badan dikarenakan kepemilikan dan modal saham yang dikuasai suatu badan lainnya sebesar lebih dari $25 \%$, atau badan yang memiliki saham. Tunnelling dapat diimplementasikan berupa pengiriman berupa transfer ke parent company dari pihak yang bersangkutan dan pembagian dividen transaksi pihak terkait dengan tujuan guna menjalankan pembayaran dividen karena pengalokasian dividen kepada parent company dan shareholders minoritas lainnya diwajibkan bagi perusahaan yang terdaftar di BEI. Shareholders minoritas perusahaan sering memperoleh kerugian ketika harga transfer memberikan keuntungan kepada parent company atau shareholders pengendali (Suandy, 2011).

Kelanjutan transfer pricing tidak lepas dari kesejagatan (globalisasi) yang berposisi mengurangi serta mentiadakan kendala antar negara dalam memperluas "arus barang, jasa, modal, dan sumber daya manusia". Transaksi sesuai azas kewajaran dan kelaziman terjadi apabila dengan indikator yang independen (tidak ada hubungan istimewa) harga yang berlaku berlandaskan kekuatan pasar (hukum permintaan dan penawaran). Transaksi dengan pihak hubungan istimewa (associated enterprises), maka dapat terjadi harga yang berlaku menjadi tidak sesuai azas kewajaran dan kelaziman (arm's length principle) karena kekuatan pasar tidak berlaku semestinya. Tunnelling dapat diimplementasikan kedalam format transfer ke parent company melalui pihak yang ikut serta. Ketika harga dirasa memberikan gain atau keuntungan parent company atau pemegang saham 
pengendali sehingga shareholders minoritas perusahaan seringkali mendapatkan kerugian (Lo et al., 2010).

Berdasarkan literatur praktik transfer pricing, tax minimization pada umunnya melalui menggeserkan biaya maupun penghasilan perusahaan yang terkait dengan transaksi perihal related party atau afiliasi dengan lawan transaksi yang memiliki tarif pajak lebih berbeda atau bahkan corporate income tax rate yang lebih rendah. Popularitas perusahaan multinasional dalam perdagangan internasional telah menggenjot untuk menjelaskan barang apa yang mereka hasilkan, di mana mereka mencari produksi dan bagaimana mereka menanggapi insentif dan strategi yang ditetapkan oleh pemerintah nasional dan subnasional. Penggunaan potensi mereka dari "transfer" harga untuk transaksi pihak terkait telah, khususnya, ditarik perhatian luas dari praktisi maupun akademisi. Mengingat besarnya volume AS dan perdagangan global yang terjadi dalam perusahaan multinasional, dampak potensial dari harga transfer substansial, memiliki kemampuan untuk mempengaruhi statistik perdagangan resmi, agregat akun nasional dan perkiraan inflasi dan pertumbuhan produktivitas melalui efeknya pada harga impor dan ekspor (Bernard et al.,2006)

Selain stimulus tax minimization, kepemilikan saham mempengaruhi ketetapan dalam menjalankan transfer pricing. Di Indonesia, struktur kepemilikan terkonsentrasi dengan jumlah pemilik yang berjumlah lebih sedikit memungkinkan terjadinya kontradiksi keagenan (agency theory) antara mayoritas dan minoritas shareholders. Kemunculan mayoritas dan minoritas shareholders mengarahkan atau menyebabkan kepemilikan saham di Indonesia lebih terpusat atau terkonsentrasi (Johnson et al., 2000)

Klassen, et al (2017) menyatakan adanya beberapa respon berkaitan dengan transisi pajak di Eropa, Kanada dan Amerika Serikat melalui pergeseran income yang dilakukan oleh perusahaan multinasional, seperti MNC (multinational companies) melakukan perpindahan penerimaan dari Kanada ke Amerika Serikat, sedangkan dalam rangka menurunkan biaya pajak di Eropa melalui perpindahan penerimaan dari Amerika Serikat ke Eropa.

\section{KERANGKA TEORITIS DAN PENGEMBANGAN HIPOTESIS}

Jensen \& Meckling (1976) menuturkan terkait interaksi keagenan tekandung pada agency theory dimana antara pemilik sumber daya ekonomis dengan manager yang melakukan pengendalian sumber daya sehingga perusahaan dilambangkan sebagai himpunan kontrak (nexus of contract).

Tunneling didefinisikan sebagai suatu perilaku shareholders mayoritas memprioritaskan kepentingan pribadi (sendiri) melalui transfer assets atau profit perusahaan, akan tetapi biaya ditanggungjawabkan kepada shareholders minoritas (Hartati et al., 2015). Johnson et al (2000) bahwa tunneling diklasifikasikan menjadi dua format. Pertama, yakni self-dealing, kepentingan sendiri melalui transfer sumber daya guna mengendalikan shareholders. Dimana transaksi tersebut termasuk penipuan langsung atau pencurian, yang ilegal dimana-mana meskipun sering tidak terdeteksi atau dihukum), tetapi juga penjualan dan kontrak 
aset seperti transfer pricing memberikan keuntungan bagi shareholders pengendali, kompensasi eksekutif yang berlebihan, jaminan pinjaman, pengambilahan peluang perusahaan dan seterunya. Kedua, shareholders pengendali meningkat bagiannya dari perusahaan tanpa mentransfer aset apa pun melalui minoritas pembekuan, perdagangan orang dalam, atau transaksi keuangan lainnya itu mendiskriminasikan minoritas. Disini kami fokus pada jenis tunneling pertama, tapi kami sebutkan yang bagian kedua di bagian akhir. Mutamimah (2009) menyatakan tunneling dapat terjadi melalui strategi merger dan akuisisi oleh pemilik saham mayoritas terhadap minoritas. Transfer pricing didefinisikan sebagai pertukaran antardisidional perihal harga jual khusus guna mencatat biaya bagi divisi pembeli (buy division) dan pendapatan bagi divisi penjual (selling division) (Lingga, 2012). Transfer pricing atau intercorporate pricing, intracompany pricing, interdivisional atau internal pricing adalah harga yang diperhitungkan guna keperluan pengelolaan manajemen atas transfer barang dan jasa antar anggota. Transfer pricing melambangkan suatu strategi perusahaan menjalankan transaksi dengan pihak afiliasi (related party). Ketika perusahan mentransfer barang, properti atau jasa tidak berwujud ke perusahaan terkait (lawan transaksi) harga yang ditanggungkan sebagai harga transfer. Perlakuan pajak terkait transfer pricing diatur ke dalam aturan yang mengatur transaksi hubungan istimewa. OECD mengimplikasikan tiap negara guna menyempurnakan regulasi (undang-undang) domestik masing-masing negara dengan tatanan perihal transfer pricing sebagai pedoman perusahaan multinasional dan DJP (direktorat jenderal pajak) dalam memecahkan persoalan terkait transfer pricing. Ketetapan mengenai transfer pricing telah tersiarkan kedalam peraturan perpajakan di Indonesia sebagaimana "UU Pajak Penghasilan (PPh)" dan "UU Pertambahan Nilai (PPN)" dimana telah termasuk tools untuk kompilasi transfer pricing. Berlandaskan "pasal 1 ayat (8)" "Peraturan Direktorat Jenderal Pajak Nomor PER-32/PJ/2011", mendefinisikan penentuan harga transfer (transfer pricing) yaitu, penentuan atau determinasi biaya transaksi antarpihak yang memegang hubungan istimewa. Lingga (2012) bahwa penetapan transfer pricing seharusnya sesuai dengan struktur organisasi perusahaan guna mencapai strategi dan tujuan perusahaan. Pada umumnya transfer pricing berkaitan dengan tujuan perusahaan melalui penjualan produk dan jasa, namun distimulus untuk meminimalisir anggaran dan unit yang membeli produk atau jasa sehingga menghasilkan input yang efisien (Lingga, 2012). Transfer pricing bertujuan untuk, mengikhtiarkan profit/margin sehingga pembagian dividen dan pemenuhan pajak menjadi rendah. Kedua, guna memark-up profit/margin untuk merestorasi (window-dressing) laporan keuangan (Lingga, 2012). Dengan merebaknya praktik global ini, negara dirugikan karena banyak perusahaan asing di Indonesia melakukan praktek transfer pricing sehingga kualitas auditor sangat diperlukan, sehingga perlu adanya standard auditing sebagai pedoman bagi auditor dalam menjalankan kewajiban profesionalnya (Rachmawati, 2008)

\subsection{Pengaruh tunnelling incentive terhadap ketetapan transfer pricing}

Keputusan melakukan transfer pricing dapat dipengaruhi oleh kepemilikan saham. Struktur kepemilikan di Indonesia terkonsentrasi pada sedikit 
pemilik sehingga terjadi konflik keagenan antara pemegang saham mayoritas dengan pemegang saham minoritas. Kepemilikan saham di Indonesia cenderung terkonsentrasi menyebabkan munculnya pemegang saham pengendali dan minoritas (La Porta et al., 2000 dalam Hartati 2015). Hartati. et al., (2015) "pengaruh tunneling incentive terhadap ketetapan transfer pricing dimana transaksi pihak afiliasi merupakan cara memindahkan kekayaan kepada shareholders mayoritas". Sebab perusahaan wajib mengalokasikan dividen kepada parent company dan shareholders minoritas lainnya. Yuniasih et al, (2012) "menemukan bahwa tunneling incentive berpengaruh positif pada ketetapan transfer pricing", kondisi dimana terpusatnya kepemilikan saham perusahaan publik di Indonesia sehingga tindakan tunnelling cenderung dilakukan oleh shareholders mayoritas. Maka dikembangkan hipotesis sebagai berikut:

H1: Tunneling incentive memiliki pengaruh positif terhadap ketetapan transfer pricing

\subsection{Pengaruh debt convenant terhadap ketetapan transfer pricing}

Debt convenant memberi pengaruh ketetapan perusahaan dalam menjalankan transfer pricing. Dilihat dari the debt convenant hipothesis perusahaan jika rasio hutang yang melebihi batas maka berusaha mengindari terjadinya pelanggaran kontrak hutang dengan memilih kiat metode akuntansi yang meningkatkan laba perusahaan. Salah satu cara transfer pricing adalah pemilihan prosedur akuntasi melalui laporan perubahan laba periode berikutnya ke periode sekarang. Richardson. et. al. (2013) menyatakan bahwa debt convenant mempunyai pengaruh signifikan positif dengan ketetapan perusahaan dalam menjalankan transfer pricing (Nuradila \& Wibowo, 2018)

H2: Debt convenant memiliki pengaruh positif terhadap ketetapan transfer pricing

\subsection{Pengaruh tax minimization memoderasi tunnelling incentive terhadap ketetapan transfer pricing}

Tax minimization merupakan tindakan yang diambil oleh perusahaan agar mengurangi beban pajak perusahaan. Rahayu, (2010) menjumpai cara transfer pricing dengan cara kiat memanipulasi beban biaya transaksi antar perusahaan yang memegang hubungan istimewa bertujuan mengecilkan beban pajak terutang. Mangoting, (2000) berpendapat praktik transfer pricing banyak dilakukan perusahaan untuk mengurangi pembayaran pajak. Hal sama yang menyupai menjumpai memicu perusahaan untuk menjalankan transfer pricing dipengaruhi beban pajak yang semakin besar dengan tujuan menekan beban (Yuniasih et al., 2012). apabila perusahaan terjadi tunneling, maka akan mengorbankan hak shareholders minoritas dengan menjalankan transfer pricing, tebukti dengan diperkuat adanya stimulus tax minimization. Dengan stimulus dapat mengurangi beban pajak akan memperkuat hubungan tunneling incentives dengan transfer pricing (Nuradila \& Wibowo, 2018). Penelitian yang sama menemukan bahwa beban pajak yang semakin besar memicu perusahaan untuk melakukan transfer pricing dengan harapan dapat menekan beban tersebut (Yuniasih, 2012) 
H3: Tax minimization dapat memoderasi pengaruh positif dalam hubungan Tunneling incentives terhadap ketetapan transfer pricing.

\subsection{Pengaruh tax minimization memoderasi debt convenant terhadap ketetapan transfer pricing}

Melonjaknya angka hutang dapat menimbulkan pimpinan menggunakan strategi meningkatkan laba perusahaan dengan menggunakan transfer pricing. Terjadinya hutang perusahaan digunakan manajer untuk mengecilkan biaya pajak perusahaan dengan cara tax minimization yaitu meningkatakan anggaran Bunga sehingga laba perusahaan dapat meningkat (Nuradila \& Wibowo, 2018)

H4: Tax minimization sebagai Pemoderasi pengaruh positif dalam hubungan Debt convenant terhadap ketetapan Transfer pricing

\section{METODE RISET}

Rancangan dipergunakan merupakan jenis penelitian eksplanatif asosiatif, yakni penelitian yang memaparkan hubungan atau keterkaitan serta kedudukan antar satu atau lebih variabel lainnya. Pemilihan sampel berlandaskan purposive sampling pada unit analisis industri manufaktur yang tercatat dalam Bursa Efek Indonesia dengan horizon waktu sejak tahun 2014 sampai 2017. Sumber Penelitian berasal dari laporan keuangan perusahaan. Alat yang digunakan untuk menjalankan pengolahan yaitu alat regresi data panel dengan menggunakan program Eviews 8.1 dalam menganalisis pengaruh tunnelling incentive, debt convenant terhadap ketetapan transfer pricing dengan tax minimization sebagai pemoderasi.

\subsection{Populasi dan Sampel}

Penelitian ini menggunakan objek perusahaan manufaktur yang tercatat di BEI tahun 2014-2017. Pengambilan sampel yang digunakan penelitian ini dilakukan dengan metode purposive sampling dengan kriteria sebagai berikut:

1. Penelitian ini menggunakan perusahaan multinasional sektor manufaktur yang tercatat di BEI periode 2014-2017 dikarenakan perusahaan manufaktur menjalankan transfer pricing.

2. Perusahaan yang selalu melaporkan Laporan Keuangan BEI dalam periode 2014-2017 dan tidak mengalami kerugian dan menggunakan mata uang rupiah (IDR). Jika perusahaan mengalami kerugian maka perusahaan tidak dikenakan atau diwajibkan untuk membayar pajak, sehingga perusahaan yang mengalami kerugian akan dibuang dari sampel guna mencapainya relevansi penelitian ini.

3. Contoh perusahaan yang dikuasai oleh $20 \%$ dari kepemilikan perusahaan asing atau lebih. Sesuai dengan PSAK 15 yang menyatakan bahwa shareholders pengendali merupakan objek yang memiliki saham atau efek yang bersifat ekuitas sebesar 20\% atau lebih. Apabila entitas memiliki pengaruh langsung maupun tidak langsung misal, entitas anak $20 \%$ atau lebih hak suara investee, maka entitas dianggap memilliki pengaruh signifikan. 


\subsection{Metode Analisis Data}

Prosedur analisis data yang dilakukan saat meneliti menggunakan alat analisis regresi data panel. Analisis regresi data panel ialah alat statistika yang dipergunakan untuk menguji penggabungan data antara data cross section dan data time series dimana unit cross section yang sama diukurkan pada waktu yang berbeda maupun pada data beberapa sampel yang sama diamati dalam kurun waktu tertentu. Regresi panel pada penelitian ini, dirumuskan dalam persamaan:

$$
\begin{gathered}
\text { TP }=\underset{\alpha}{\alpha}+\beta_{1} \text { TUN }+\beta_{2} \text { DEB }+\beta_{3} \text { TUN.TMINIM }+\beta_{4} \text { DEB.TMINIM }+\beta_{5} \\
\text { BONUS }+\beta_{6} \text { ROE }+\beta_{7} \text { AUD_EKS }+\beta_{8} \text { RPT }+\beta_{9} \text { SIZE }+\varepsilon
\end{gathered}
$$

Keterangan: $\mathrm{TP}=$ transfer pricing, $\mathrm{TUN}=$ Tunnelling Incentive $; \mathrm{DEB}=$ Debt convenant; TMINIM = Tax Minimization; BONUS = Bonus Mechanism $; \mathrm{ROE}=$ Return of Equity; AUD_EKS = Auditor Eksternal; RPT= Related Party Transactions; SIZE = Firm Size.

\subsection{Pengukuran Variabel}

Variabel penelitian ini adalah transfer pricing. Transaksi atas produksi atau jasa antar divisi berbeda pada perusahaan sama atau antar perusahaan yang memiliki hubungan afiliasi dapat dikategorikan menjadi transfer pricing (Yuniasih et al., 2012). Transfer pricing diproksikan dengan nilai Related Party Transaction (RPT) dalam (Nuradila \& Wibowo, 2018)

$$
\text { Nilai } R P T=\frac{\text { Piutang RPT }}{\text { Total Piutang }} \times 100 \%
$$

Keterangan:

RPT $=$ Related Party Transaction

Variabel independen dalam penelitian ini adalah tunnelling incentive dan debt convenant.

Tunnelling Incentive diukur dengan pada persentase kepemiikan saham yang melebihi $20 \%$. Hal ini harus sesuai dengan "Undang- Undang Pasar Modal No.I. H.1", menjelaskan shareholders pengendali adalah pihak yang memiliki saham atau efek yang bersifat ekuitas sebesar 20\% atau lebih (Mutamimah, 2009). "PSAK No.15" menyatakan adanya pengaruh signifikan dari shareholders dengan persentase kepemilikan sebesar 20\% atau lebih (Yuniasih et al., 2012).

$$
\begin{aligned}
& \text { Kepemilikan saham asing } \\
& \qquad=\frac{\text { Jumlah Kepemilikan hak asing }}{\text { Total saham yang beredar }} \times 100 \%
\end{aligned}
$$

Melambangkan strategi estimasi akuntansi guna mengoptimalkan pemasukan anggaran diberikan pimpinan secara kiat meningkatkan profit perusahaan (Hartati et al., 2015). Bonus mechanism dikukur dengan indeks trend laba bersih (ITRENDLB) dalam (Nuradila \& Wibowo, 2018)

$$
D E R=\frac{\text { Total Debt }}{\text { Total Equity }} \times 100 \%
$$


Keterangan:

$\mathrm{DER}=$ Debt to Equity

Variabel Moderasi dalam penelitian ini adalah tax minimization, yang berarti suatu cara peminimalan beban pajak terutang melalui mekanisme mengirim biaya terakhir melalui transfer pendapatan ke negara dengan tarif pajak terendah (Hartati. et al., 2015). "Tax minimization diproksikan dengan effective tax rate /ETR” (Nuradila \& Wibowo, 2018):

$$
E T R=\frac{\text { Tax Expense }}{\text { Laba Kena Pajak }} \times 100 \%
$$

Keterangan:

ETR $=$ Effecive Tax Rate

Variabel Kontrol dalam penelitian in diantaranya: Bonus Mechanism, Return on Equity, The Auditor Quality, Related Party Sales, Firm Size.

\section{Bonus Mechanism}

Merupakan salah satu metode perhitungan akuntansi dalam rangka meningkatkan pendapatan bonus oleh pimpinan melalui peningkatan laba perusahaan secara global atau keseluruhan (Hartati et al., 2015):

$$
\text { BONUS }=\frac{\text { Laba bersih tahun } \mathrm{t}}{\text { Laba bersih tahun } \mathrm{t}-1} \times 100 \%
$$

Return on Equiy

Menurut penelitian Lo et al (2010) diukur dengan return on equity, Untuk mengontrol kemungkinan efek dari profitabilitas perusahaan pada ketetapan penentuan harga transfer.

$$
\text { Retrun of Equity }=\frac{\text { Net Income }}{\text { Total Equity }}
$$

\section{The Auditor Quality}

Kualitas audit berkaitan erat dengan koefisien respon laba masa depan (FERC) karena informatifan laba laporan keuangan yang teraudit lebih baik daripada laporan keuangan tidak teraudit. Kualitas audit dapat meningkatkan kredibilitas dari informasi laporan keuangan (Murwaningsari, 2014)

\section{Related Party Transcation}

Jika RPT adalah tinggi, ini mungkin menunjukkan pelanggan RPT akan memiliki kekuatan tawar yang kuat dan mengarah ke yang lebih rendah rasio laba kotor. Alternatif lain, menjual ke pelanggan RPT tunggal yang besar dapat mengarah ke unit yang lebih rendah biaya melalui produksi yang lebih lama berjalan? dan, oleh karena itu, margin kotor lebih tinggi (Lo et al., 2010)

$$
R P T=\frac{\text { The amount of related party sales }}{\text { Total sales }}
$$


Vol.2, No. 2, Mei. 2019

Keterangan: $R P T=$ Related Party Transaction.

Firm Size

TSIZE diukur dengan penjualan pihak terkait atas penjualan kepada lima pelanggan terbesar perusahaan, dapat menggunakan LN dari total assets (Lo et al., 2010):

SIZE $=$ LOG $($ Total Assets $)$

\section{ANALISIS DAN PEMBAHASAN}

Penelitian ini menggunakan data berformat data panel yang dianalisis dengan tiga model estimasi, yaitu common effect, fixed effect dan random effect. Estimasi tersebut digunakan untuk memilih model estimasi yang lebih akurat dalam menjelaskan model penelitian ini.

Uji Chow adalah pengujian yang pertama dilakukan dalam menganalisis model estimasi yang akan diperlukan dalam pemilihan model common effect atau fixed effect. Nilai uji chow dapat dilihat dari nilai Prob. "Cross-section Chi-square".

Tabel 4.1

Hasil Uji Chow

\begin{tabular}{llll}
\hline Metode & $\begin{array}{l}\text { Prob.Chi- } \\
\text { Square }\end{array}$ & Keputusan & \multicolumn{2}{l}{ Keterangan } \\
\hline Uji Chow & $0,00<0,05$ & Ha diterima & $\begin{array}{l}\text { Fi ed } \\
\text { Model }\end{array}$ \\
\hline
\end{tabular}

Berlandaskan tabel di atas, hasil pengujian pada uji Chow menunjukkan nilai Prob. Cross-section "Chi-square sebesar 0,00" yang lebih kecil dari 0,05 maka dapat dinyatakan bahwa model yang terpilih adalah Fixed Effect Model. Setelah dilakukan pengujian pertama, maka selanjutnya dilakukan pengujian kedua yaitu uji Hausman untuk memilih antara Fixed Effect Model atau Random Model.

Tabel 4.2

Hasil Uji Hausman

\begin{tabular}{llll}
\hline Metode & $\begin{array}{l}\text { Prob.Chi- } \\
\text { Square }\end{array}$ & Keputusan & Keterangan \\
\hline Uji Hausman & $0,00<0,05$ & Ha diterima & Fi ed Effect Model \\
\hline
\end{tabular}

Berlandaskan tabel di atas, hasil pengujian pada uji Hausman menunjukkan nilai Prob. Cross section "Chi square sebesar 0,00 "yang $\leq 0,05$ maka dinyatakan model yang terpilih adalah Fixed Effect Model. Dengan demikian, dapat disimpulkan bahwa model estimasi yang lebih tepat atau yang terbaik dalam menjelaskan model penelitian ini adalah Fixed Effect Model. 


\subsection{Uji Koefisien Determinasi}

Uji koefisien determinasi $\left(\mathrm{R}^{2}\right)$ bertujuan menguji bagaimana kemampuan variabel terikat (respons) dijelaskan oleh variabel prediktor dengan melihat besarnya nilai Adjusted $R^{2}$ "Nilai koefisien determinasi $\left(\mathrm{R}^{2}\right)$ berada di antara $0 \mathrm{~s} / \mathrm{d}$ 1 sehingga semakin meningkat nilai Adjusted $\mathrm{R}^{2}$, maka tinggi juga kemampuan variabel independen dalam menjelaskan variabel dependen. Tabel 4.3 di bawah ini menunjukkan hasil pengujian koefisien determinasi.

Tabel 4.3

Hasil Uji Koefisien Determinasi

\begin{tabular}{ccc}
\hline R-Squared & Adjusted R Squared \\
\hline & 0,99 & 0,98 \\
\hline
\end{tabular}

Berlandaskan tabel 4.3 di atas, hasil uji koefisien determinasi (Goodness of Fit) pada regresi data panel diperoleh nilai Adjusted $R^{2}$ sebesar 0,98 "berarti seluruh variabel independen mampu menjelaskan variasi dari variabel dependen sebesar 98\%", sedangkan sisanya sebesar 2\% (100\% - 98\%) dapat dilihat dengan faktor-faktor lain yang tidak berada dalam model.

\subsection{Uji Signifikansi Koefisien Regresi Serentak (F-test)}

Uji signifikansi koefisien regresi serentak (F-test) bertujuan untuk menguji sekiat bersama - sama seberapa besarnya pengaruh variabel prediktor yang terdapat pada model regresi terhadap variabel terikatnya (respons). Tabel 4 menunjukkan hasil pengujian signifikansi koefisien regresi serentak (F-test).

Tabel 4.4

Hasil Uji Serentak (F-Test)

\begin{tabular}{|c|c|c|c|}
\hline Model Regresi & F Statistic & Prob F Statistic & Keterangan \\
\hline Regresi Data Panel & 123,45 & 0,00 & Signifikan \\
\hline
\end{tabular}

Sumber: Data diolah penulis

Berlandaskan tabel 4.6.di atas, nilai $F$-statistic sebesar 123.45 dengan nilai prob. (F-statistic) yaitu $0,00<$ alpha 0,05 dapat diartikan bahwa sekiat serentak seluruh variabel independen yaitu tunnelling incentive dan debt convenant dengan tax minimization sebagai pemoderasi memiliki pengaruh terhadap transfer pricing. Hal tersebut sesuai dengan kriteria pengambilan ketetapan dalam uji $\mathrm{F}$ statistik, apabila angka signifikansi dari $\mathrm{F}$ lebih rendah dari angka kepercayaan 0,05 maka variabel independen sekiat simultan melambangkan signifikan variabel dependen.

\subsection{Uji Signifikansi Koefisien Regresi Parsial (T-test)}

Uji signifikansi koefisien regresi parsial (T-test) dilakukan untuk mengetahui arah hubungan serta ada atau tidak pengaruh masing-masing variabel 
independen terhadap variabel dependen. Berikut tabel 4.5 menunjukkan hasil pengujian signifikansi koefisien regresi parsial (T-test).

Tabel 4.5

Hasil Uji Parsial (T-test)

\begin{tabular}{llccc}
\hline VARIABEL & PREDIKSI & KOEFIsien & PROB. & KESIMPULAN \\
TUN & + & 0,0497 & 0,029 & Berpengaruh signnifikan (-) \\
DEB & + & $-0,001$ & 0,001 & Tidak berpengaruh signnifikan (-) \\
TUN_TMINIM & + & $-0,105$ & 0,778 & Tidak berpengaruh signnifikan (-) \\
DEB_TMINIM & + & $-0,009$ & 0,981 & Tidak berpengaruh signnifikan (-) \\
BONUS & $+/-$ & 0,002 & 0,878 & Tidak berpengaruh signnifikan (+) \\
ROE & $+/-$ & $-0,032$ & 0,717 & Tidak berpengaruh signnifikan (-) \\
AUD_EKS & $+/-$ & 0,046 & 0,424 & Tidak berpengaruh signnifikan (+) \\
RPT & $+/-$ & 0,040 & 0,9062 & Tidak berpengaruh signnifikan (+) \\
SIZE & $+/-$ & $-0,206$ & 0,144 & Tidak berpengaruh signnifikan $(-)$
\end{tabular}

Sumber: Data diolah penulis

Notes: TUN= Tunnelling Incentive $;$ DEB $=$ Debt convenant $;$ TMINIM $=$ Tax Minimization; BONUS = Bonus Mechanism; ROE = Return of Equity; AUD_EKS $=$ Auditor Eksternal; RPT $=$ Related Party Transactions; $\mathrm{SIZE}=$ Firm Size .

Berlandaskan tabel 4.5 hasil pengujian parsial (T-test) dalam penelitian ini menggunakan pengujian One-tailed untuk hipotesis yang sudah jelas arah hubungannya positif atau negatif sehingga nilai Prob masih harus diklasifikasikan. Berikut dijelaskan hasil pengujian dari masing-masing variabel independen meliputi: Hipotesis kesatu (Ha1) menyatakan tunnelling berpengaruh signifikan positif terhadap transfer pricing "Hasil pengujian dalam penelitian ini menyatakan bahwa tunneling berpengaruh signifikan positif terhadap transfer pricing sehingga Hal diterima". Hasil pengujian dalam penelitian ini sejalan dengan penelitian Yuniasih et. al., (2012) menjelaskan bahwa tunnelling incentive berpengaruh positif pada ketetapan transfer pricing. Hal ini konsisten pada hipotesis yang diajukan. Tujuan untuk memberikan kepunyaan pada shareholders rata-rata daripada pembayaran dividen, hal dikarenakan perusahaan harus mengalokasikan dividen kepada parent company dan shareholders minoritas lainnya. Yuniasih. et al., (2012) menyebutkan kondisi langka kepemilikan saham pada perusahaan publik di Indonesia cenderung terpusat, hingga terjadi kemiripan shareholders kebanyakan agar menjalankan tunneling.

Hipotesis kedua (Ha2) menyatakan tunnelling berpengaruh signifikan positif terhadap transfer pricing. Hasil pengujian dalam penelitian ini menyatakan bahwa debt convenant mempunyai pengaruh tidak signifikan negative terhadap transfer pricing sehingga Ha2 ditolak. Hasil pengujian Sari \& Mubarok (2018) menyatakan debt convenant memiliki pengaruh negative dan 
tidak signifikan terhadap transfer pricing. Hasil ini tidak sesuai dengan hipotesis yang diajukan. Angka utang yang tinggi dapat meningkatkan resiko kekurangan dalam memenuhi kewajiban membayar hutang bagi perusahaan. Hal ini juga memungkinkan adanya kenaikkan biaya bunga dan kenaikan biaya pajak, di mana alokasi hutang perusahaan diperuntukkan bagi keperluan investasi sehingga mendapatkan penghasilan di luar usaha perusahaan dan membuat laba yang didapat perusahaan naik dan mempengaruhi kenaikan beban pajak yang ditanggung perusahaan.

Hipotesis ketiga (Ha3) menyatakan tax minimization dapat memoderasi pengaruh tunnelling incentive memiliki pengaruh signifikan positif terhadap transfer pricing. Hasil pengujian penelitian ini menyatakan bahwa debt convenant berpengaruh tidak signifikan negatif terhadap transfer pricing sehingga Ha4 ditolak. Hasil pengujian dalam penelitian tidak dengan penelitian yang dilakukan Yuniasih et al., (2012), tax minimization memoderasi secara signifikan pengaruh tunnelling incentive terhadap ketetapan transfer pricing pada perusahaan multinasional. Hasil ini belum konsisten dengan hipotesis yang diajukan. Hipotesis keempat (Ha4) menyatakan tax minimization dapat memoderasi pengaruh debt convenant signifikan positif terhadap transfer pricing. Hasil pengujian dalam penelitian ini menyatakan bahwa debt convenant berpengaruh tidak signifikan negatif terhadap transfer pricing sehingga $\mathrm{Ha} 4$ ditolak. Hasil pengujian dalam penelitian ini sejalan akan tetapi signifikasi yang berbeda dengan penelitian yang dilakukan (Nuradila \& Wibowo, 2018). Berarti ketika perusahaan memiliki tingkat leverage tinggi maka kecenderungan perusahaan dalam menjalankan transfer. Bonus Mechanism(BONUS) tidak berpengaruh signifikan positif terhadap ketetapan transfer pricing.

Didukung oleh Lo et. al., (2010) memberi pernyataan mengenai bonus plan tidak mempunyai pengaruh pada ketetapan transfer pricing. Biaya pembayaran Bonus dari rumusan profitabilitas mempunyai pengaruh terhadap ketetapan transfer pricing. Untuk memberikan bonus kepada direksi, pemilik perusahaan akan memantau hasil kerja direksi dalam mengelola perusahaanya. Penelitian ini tidak didukung Hartati et al., (2015) kiat menjalankan transfer pricing. Return On Equity (ROE) tidak memiliki pengaruh signifikan negatif kepada ketetapan transfer pricing. Hal ini sesuai dengan penelitian Richardson et al., (2013) yang menyatakan bahwa perusahaan yang mengalami pendapatan besar akan seiring dengan sumber pendanaan dalam yang lebih besar sehingga penggunaan modal internal diutamakan lebih dahulu seperti dalam format laba dari pendapatan yang diterima perusahaan dari menggunakan anggaran luar atau anggaran yang diperoleh pihak luar yaitu hutang sehingga angka hutang yang dipakai oleh perusahaan sangat rendah serta akan memperkecil resiko timbulnya kerugian dan hutang yang tinggi. Hasil penelitian ini menunjukkan keterkaitan antara profitabilitas berupa laba perusahaan terhadap transfer pricing yang dilakukan karena ada hal yang memungkinkan perusahaan memindahkan penghasilan parent company ke anak perusahaan yang mempunyai tarif pajak rendah. salah satu cara untuk menurunkan laba yaitu dengan menggunakan transfer pricing 
Auditor Eksternal (Aud_Eks) tidak memiliki pengaruh signifikan positif pada ketetapan transfer pricing. Penelitian ini sejalan dengan Lo et al., (2010) menyatakan bahwa kualitas auditor tidak berpengaruh signifikan. Related Party Transactions (RPT) tidak memiliki pengaruh signifikan positif pada ketetapan transfer pricing. Sejalan dengan Lo. et al., (2010) menyatakan bahwa kualitas auditor tidak berpengaruh signifikan. Diukur dengan jumlah pihak terkait penjualan dari total penjualan. Jika RPT adalah tinggi, ini mungkin menunjukkan pelanggan RPT akan memiliki kekuatan tawar yang kuat dan mengarah ke yang lebih rendah rasio laba kotor. Alternatif lain, menjual ke pelanggan RPT tunggal yang besar dapat mengarah ke unit yang lebih rendah biaya melalui produksi yang lebih lama berjalan dan, oleh karena itu, margin kotor lebih tinggi. Firm Size (Size) tidak memiliki pengaruh signifikan negatif pada ketetapan transfer pricing. Penelitian ini sejalan dengan Lo et al., (2010) menyatakan bahwa firm size tidak berpengaruh signifikan negatif. Penelitian ini tidak sejalan dengan Richardson et al., (2013) sehingga didukung oleh hasil perusahaan yang lebih besar masuk dalam memanipulasi harga transfer yang lebih tinggi. Jadi suatu perusahaan bisa dikatakan perusahaan besar, jika aset yang dimilikinya juga besar.

\section{SIMPULAN}

Hasil kesimpulan yang diperoleh adalah agar mendapatkan bukti empiris pengaruh variabel independen, yaitu Tunneling incentive (TUN) dan Debt convenant (DEB) terhadap ketetapan Transfer pricing (TP). Dari hasil analisis dan pembahasan yang telah dilakukan sebelumnya, maka dapat disimpulkan sebagai berikut: Dari hasil penelitian menunjukkan variabel TUN memiliki pengaruh signifikan dengan ketetapan transfer pricing. Artinya, terjadi perubahan pada variabel independen yaitu TUN secara simultan akan berpengaruh pada ketetapan perusahaan untuk menjalankan transfer pricing. Secara Parsial hasil penelitian ini menunjukkan sebagai berikut: Tunneling incentive (TUN) memiliki pengaruh signifikan positif pada ketetapan transfer pricing. Debt convenant (DEB) tidak memiliki pengaruh signifikan negatif pada ketetapan transfer pricing. Tunnelling Incentive memoderasi Tax minimization (TUN_TMINIM) tidak berpengaruh signifikan negatif terhadap ketetapan transfer pricing. Debt convenant memoderasi tax minimization (DEB_TMINIM) tidak berpengaruh signifikan negatif terhadap ketetapan transfer pricing. Bonus Mechanism (BONUS) tidak berpengaruh signifikan positif pada ketetapan transfer pricing. Return on Equity (ROE) tidak memiliki pengaruh signifikan negatif pada ketetapan transfer pricing. Auditor Eksternal (Aud_Eks) tidak berpengaruh signifikan positif terhadap ketetapan transfer pricing. Related Party Transactions (RPT) tidak berpengaruh signifikan positif terhadap ketetapan transfer pricing. Firm Size (Size) tidak berpengaruh signifikan negatif terhadap ketetapan transfer pricing. 
Vol.2, No. 2, Mei. 2019

\section{KETERBATASAN DAN SARAN}

Objek yang dipakai pada penelitian menggunakan perusahaan manufaktur yang tercatat di Bursa Efek Indonesia pada tahun 2014-2017. Penelitian ini hanya menguji tunnelling incentive dan debt convenant. Selain itu, penelitian ini hanya berbasis pada data sekunder.

Dalam penelitian selanjutnya, dapat menambah contoh scope pada Negara ASEAN karena pada faktanya terjadi praktek transfer pricing dengan metode special purpose vehicle (SPV). Selain itu, penggunaan data primer dalam penelitian ini dari sisi investor, manajemen dan auditor sehingga hasil lebih aplikatif dan faktuial. dalam mengambil ketetapan untuk menjalankan transfer pricing. Untuk yang mau berinvestasi, ada baiknya mengecek laporan keuangan yang ditebitkan oleh perusahaan, agar investor bisa mengambil ketetapan dalam berinvestasi.

\section{DAFTAR PUSTAKA}

Bernard, A. B., Jensen, J. B., \& Schott, P. K. (2006). Transfer Pricing by U.S.Based Multinational Firms. Ssrn, (603). https://doi.org/10.2139/ssrn.924573

Hartati, W., Desmiyawati, \& Julita. (2015). Tax Minimization, Tunneling Incentive dan Mekanisme Bonus Terhadap Keputusan Transfer Pricing Seluruh Perusahaan yang Listing di Bursa Efek Indonesia. Proceding SNA XVIII, 241-246. https://doi.org/10.1109/PAPCON.2001.952974

Jensen, M. C., \& Meckling, W. H. (1976). Theory of the Firm: Managerial Behavior, Agency Cost and Ownership Structure. Journal of Financial Economics, 3(4), 305-360.

Johnson, S., LaPorta, R., \& Lopes-De-Silannes, F. (2000). Tunneling. American Economic Review Papers and Proceedings, 90(20), 22-27.

Klassen, K., Lisowsky, P., \& Mescall, D. (2017). Transfer Pricing: Strategies , Practices, and Tax Minimization. Contemporary Accounting Research, 34(1), 455-493. https://doi.org/10.1111/1911-3846.12238

Lingga, I. S. (2012). Aspek Perpajakan dalam Transfer Pricing dan Problematika Praktik Penghindaran Pajak ( Tax Avoidance ). Zenit, 1(3), 209-220.

Lo, A. W. Y., Wong, R. M. K., \& Firth, M. (2010). Tax, Financial Reporting, and Tunneling Incentives for Income Shifting: An Empirical Analysis of the Transfer Pricing Behavior of Chinese-Listed Companies. Amarican Accounting Association, 32(2), 1-26. https://doi.org/10.2308/jata.2010.32.2.1

Mangoting, Y. (2000). Aspek Perpajakan Dalam Praktek Transfer Pricing. Jurnal Akuntansi \& Keuangan, 2(1), 69-82.

Murwaningsari, E. (2014). Kepemilikan Institusional Dan Kualitas Audit Future Earnings Response Coefficient. Jurnal Keuangan Dan Perbankan, Vol.18, No.2 Mei 2014, 18(2), 161-171.

Mutamimah. (2009). Tunneling Atau Value Added Dalam Strategi Merger Akuisisi Di Indonesia. Jurnal Manajemen Teori Dan Terapan, 2(2), 161182.

Nuradila, R. F., \& Wibowo, R. A. (2018). Journal of Islamic Finance and 
Accounting. Tax Minimization Sebagai Pemoderasi Hubungan Antara Tunneling Incentive, Bonus Mechanism Dan Debt Convenant Dengan Keputusan Transfer Pricing, 1(1), 63-76.

Rachmawati, S. (2008). Pengaruh Faktor Internal dan Eksternal Perusahaan Terhadap Audit Delay dan Timeliness. Jurnal Akuntansi Dan Keuangan, 10(1), 1-10. https://doi.org/10.9744/jak.10.1.pp. 1-10

Rahayu, N. (2010). Evaluasi Regulasi Atas Praktik Penghindaran Pajak Penanaman Modal Asing. Jurnal Akuntansi Dan Keuangan Indonesia, 7(1), 61-78. https://doi.org/10.2466/pr0.1982.51.3f.1111

Republik Indonesia, Undang-Undang Nomor 36 Tahun 2008 tentang Perubahan Keempat Undang-Undang Nomor 7 Tahun 1983 tentang Pajak Penghasilan Republik Indonesia, Undang-Undang Nomor 32/PJ/2011 tentang Penerapan Prinsip Kewajaran dam Kelaziman Usaha dalam Transaksi Antara Wajib Pajak dengan Pihak yang Mempunyai Hubungan Istimewa.

Richardson, G., Taylor, G., \& Lanis, R. (2013). Deteminant of Transfer Pricing Aggressiveness: Empirical Evidence From Austrakua Firm. Journal of Contemporary Accounting and Economics, 9(2), 136-150.

Sari, E. P., \& Mubarok, A. (2018). Pengaruh Profitabilitas , Pajak dan Debt Convenant Terhadap Transfer Pricing ( Studi Empiris Perusahaan Manufaktur Terdaftar di BEI Tahun 2012-2016 ). Proceding Seminar Akuntansi, 1(1), 1-6.

Suandy, E. (2011). Hukum pajak Edisi 5. Salemba Empat.

Yuniasih, N. W., Rasmini, N. K., \& Wirakusuma, M. G. (2012). Pengaruh Pajak Dan Tunneling Incentive Pada Keputusan Transfer Pricing Perusahan Manufaktur Yang Listing DI Bursa Efek Indonesia. In Journal and Proceedings of SNA-Accounting National Symposium (Vol. 15, pp. 1-23). 